\title{
PASSADO E FUTURO NO PRESENTE DOS PERCURSOS DE QUALIFICAÇÃO: \\ A EQUAÇÃO DA APRENDIZAGEM
}

Bravo Nico

Universidade de Évora/Escola de Ciências Sociais

No presente de cada estudante do ensino superior, coexistem, em simultâneo, dois tempo e duas vidas: o tempo passado, que encerra a vida que foi vivida e que o trouxe até ali; o tempo futuro, que abrirá a porta para a vida que será vivida e que ali está a ser preparada.

Estes dois tempos têm importâncias diferentes, em cada indivíduo, nas respectivas circunstâncias histórica e social, e determinarão a qualidade da vida presente, em todas as suas dimensões.

Como refere Nico (2001), apesar de estar directamente ligado a uma determinada época da vida, uma vez que ser estudante "significa, implicitamente, para os próprios ou para o exterior, pertencer à juventude" (Molinari, 1992:72), à representação de estudante encontra-se sempre associada uma imagem de transitoriedade. Erikson (1985:80) afirma mesmo que ser estudante significa pertencer-se a um grupo transitório - eventualmente, atomizado e caracterizado pelo individualismo e egoísmo (Le Bart \& Merle 1997:11) - com uma instabilidade essencial, uma metamorfose contínua, um descentramento e distanciamento em relação ao meio familiar. Também Baudelot et al (1981, cit. por Molinari, 1992:81) se referem à representação de estudante como sendo um "grupo social temporário e dividido pelos estudos, o meio familiar e as perspectivas profissionais".

Ser estudante do ensino superior é, em muitas circunstâncias, a construção de um equilíbrio diário, no qual se tentam ligar as experiências mais consolidadas do passado com 
as projecções, cada vez menos nítidas, do futuro. Chickering \& Reisser (1993:50) definem mesmo o estudante universitário como sendo um indivíduo com um presente cheio de energia, mas com um futuro e um destino incertos. É neste contexto pessoal profundamente mergulhado num determinado contexto institucional, social, económico e histórico - que ocorre a qualificação científica, técnica e cultural do estudante do ensino superior, tendo em conta a sua preparação para o seu futuro pessoal e profissional.

Na realidade, no percurso educativo geral de busca de autonomia, a frequência universitária, particularmente durante o primeiro ano, torna-se um dos principais suportes, com a ajuda do qual se vai construindo e consolidando a expressão pessoal e, muitas vezes profissional, de cada um (Dominicé, 1985:122; 1988:53). O período em que se está estudante, sendo um período de transição e de preparação para uma futura existência profissional e pessoal é, de acordo com Snyders (1993:6), um momento em que ocorrem algumas contradições entre as "experiências de vida do passado recente, a realidade do presente e as expectativas do futuro". Da união dos três vértices deste triângulo vital do estudante universitário, nascerá um polígono individualizado e único, consoante a preponderância de cada um dos vértices na vida do estudante universitário.

Uma importante alteração no perfil dos estudantes universitários tem, entretanto, vindo a ocorrer, no passado recente do ensino superior português: o crescente número de estudantes adultos que frequentam o Ensino Superior, particularmente desde que, ao nível do ensino secundário, foram implementadas novas modalidades de Educação e Formação de Adultos - destacando, aqui os processos de RVCC/Reconhecimento, Validação e Certificação de Competências -, que recuperaram, para os percursos formais de qualificação, centenas de milhares de adultos, alguns dos quais chegaram às instituições de ensino superior. 
Nos estudantes adultos, a maior idade e as experiências profissionais, familiares, políticas e cívicas, promovem uma forma diferente de se estar estudante, uma vez que as atitudes, os projectos e a capacidade de lidar com situações educativas assumem novos contornos, eventualmente, bem mais precisos.

Qualquer que seja a abordagem utilizada, parece certo que longe vão os tempos do estudante clássico, o qual, segundo Snyders (1993:23), era o indivíduo que iniciava os estudos superiores, à saída do secundário, não tendo ainda família constituída e dispondo de todo o seu tempo para estudar, numa ocupação exclusiva na sua formação. Nestes novos públicos da Universidade, começam a surgir outros perfis e tipologias discentes:

i) estudantes-trabalhadores, já frequentes no ensino superior, mas nunca com a dimensão que, presentemente, assumem;

ii) estudantes a tempo parcial (Knapper \& Cropley, 1991:48; Hodkinson, 1994:21), indivíduos que não assumem a sua vida académica como a sua dimensão mais importante e a conjugam com outras dimensões;

iii) estudantes intermitentes (El-Khawas, 1996:66), uma realidade hoje presente e que resulta da existência de indivíduos que alternam períodos de frequência académica com alguns períodos de ausência.

Estas diferentes categorias constituem-se hoje uma realidade em franca expansão no contexto universitário, facto que tem vindo a imprimir a necessidade institucional de assegurar respostas, adequadas e compatíveis, a novas exigências decorrentes das diferentes equações de vida que cada um destes grupos de estudantes encerra dentro de si.

Se existem estudantes, para quem as experiências do passado continuam preponderantes na sua vida, dificultando, tantas vezes, uma adequada transição, outros 
colegas haverá, nos quais, a negociação quotidiana das circunstâncias da vida, lhes consome todo o tempo e energia, numa tentativa constante de encontrar um equilíbrio confortável.

As preocupações com a concretização dos projectos pessoal e profissional, projectando no presente uma imagem já bem definida do futuro, são o traço dominante de uma das categorias de estudantes universitários, nos quais a dimensão pessoal estará, eventualmente, mais estabilizada: os estudantes-trabalhadores. Para os estudantes das restantes categorias, a relação construída no presente entre o passado e o futuro é, muitas vezes, um exercício difícil e de imprevisível solução.

Nesta pequena reflexão que, aqui, apresentamos acerca das circunstâncias vitais dos indivíduos do ensino superior, pensamos que uma das variáveis mais importantes da equação pessoal que cada um estabelece e resolve no seu tempo presente de estudante universitário: a dimensão vocacional.

Apesar das crescentes preocupações das instituições na adequação dos desenhos curriculares, nomeadamente nos segmentos inicial e final dos percursos de qualificação, nem sempre os estudantes encontram, no primeiro ano de frequência universitária, o prolongamento procurado e consciente dos respectivos projectos académicos. Como refere Nico (2001), se a entrada no ensino superior, para muitos estudantes, não significa uma nova etapa académica, num percurso já delineado, para outros nem significará o início de um novo projecto. Tratar-se-á, somente, da consecução, com sucesso, de uma grande finalidade, que consistia em entrar no ensino superior.

No lado oposto do percurso de qualificação, também se aplica o raciocínio anterior: presentemente, a conclusão da etapa académica no ensino significa cada vez menos o início de um percurso profissional e, cada vez mais, apenas a conclusão de um momento do processo vital de qualificação. 
Nestas condições, a dimensão vocacional dos estudantes do ensino superior, durante a respectiva caminhada académica, poderá apresentar diferentes perspectivas (Nico, 1995:17; 1996:114):

- Reforço vocacional, que ocorre quando o indivíduo ingressa e frequenta um curso desejado, que é compatível com a sua circunstância presente e com a sua auto-representação futura; situação em que o projecto académico discente entronca adequadamente no projecto profissional e este encontra o seu lugar certo no projecto pessoal, fazendo com que presente $e$ futuro se apresentem conciliáveis;

- Estrangulamento vocacional, que se verifica em situações, nas quais, o(a) estudante ingressa e frequenta um curso pouco desejado e nada compatível com a sua auto-representação futura ou com as suas circunstâncias presentes. Nestas condições, as situações de aprendizagem, que se vivem, não contribuirão, eventualmente, para os projectos profissional e pessoal, tornando pouco significativas essas situações pedagógicas, numa realidade presente incompatível com um futuro sonhado;

- Descoberta vocacional, que acontece quando o indivíduo acede e frequenta um curso não desejado, desenvolvendo, no entanto, uma atitude positiva face às experiências de aprendizagem que vai vivendo. Dessa forma, em alguns casos, assiste-se ao início da construção de novos projectos profissionais e de novas trajectórias pessoais, ocorrendo uma adaptação 
adequada da dimensão vocacional à realidade, adaptando o futuro a um presente agradável;

- Resiliência vocacional, que se manifesta em determinadas situações, nas quais se verifica a necessidade do indivíduo, não abdicando dos seus projectos vitais, encontrar as respostas mais adequadas às circunstâncias presentes, de forma a torná-las instrumentais para os seus objectivos a médio e longo-prazo, tentando adaptar o presente ao futuro de que não quer abdicar.

- Conformismo vocacional, que poderá verificar-se quando alguns indivíduos, na ausência de projectos vitais bem definidos, ou confrontados com um sentimento de incapacidade, relativamente à alteração das circunstâncias presentes, optam por uma amenização das suas perspectivas (Jarousse, 1984:207) e se conformam com a situação que vivem, num equilíbrio, relativamente estável, entre uma ausência de futuro num presente qualquer;

- Cristalização vocacional, que se torna evidente em todos aqueles estudantes que suspendem, temporariamente, a concretização dos seus projectos vitais mais profundos, aproveitando, de forma instrumental, as circunstâncias do presente, assegurando, dessa forma, a respectiva sobrevivência académica e profissional, numa estratégia de deixar passar o presente para cumprir no futuro, os projectos do passado. 
Esta dimensão vocacional - e concomitantemente curricular, no ensino superior - é, em nossa opinião, uma área fundamental para que, através de respostas curriculares personalizadas (Incyan, 1988:60; Garin, 1988:66; Stern, 1992:20) e adequadas ao perfil vocacional de cada indivíduo, se criem as condições para a existência de percursos curriculares que previnam a existência de fenómenos como o conformismo estratégico (Zeichner \& Gore, cit. por Moreira, 1993:101), o sucesso conformista (Menezes, Costa \& Paiva Campos, 1989:60) ou o conformismo realista (Nico, 1995:25).

Nenhum dos anteriores comportamentos corresponde a uma evidência de uma formação superior com a qualidade inerente à sua própria natureza e designação: superior.

\section{Referências Bibliográficas}

Chickering, A. \& Reisser, L. (1993). Education and Identity. San Francisco: Jossey-Bass Publishers.

Dominicé, P. (1985). "Ce que la vie leur a apris". In M. Finger \& C. Josso (Eds.). Pratques du récit de vie et théories de la formation. Genève: Section de Sciences de l'Éducation de l'Université de Genève: 99-122

Dominicé, P. (1988). “ O processo de formação e alguns dos seus componentes relacionais". In A. Nóvoa \& M. Finger (Orgs.). O método (auto)biográfico e a formação. Lisboa: Ministério da Saúde: 51-61

El-Khawas, E. (1996). "Student Diversity on Today's Campuses". In S. Komives \& D. Woodard (Eds.). Student Services - A Handbook for the Profession. San Francisco: JosseyBass Publishers, 64-80

Erickson, F. (1985). "Qualitative Methods in Research on Teaching". In Merlin Wittrok (Ed.). Handbook of Research on Teaching, London: Collier Macmillan Publisher.

Garin, C. (1988, Novembre). Une Cellule Active. in Le Monde de L'Educacion.

Hodkinson, K. (1994). "Flexible Provision for Student Diversity". In W. Wade et al (Eds.). Flexible Learning in Higher Education. London: Kogan Page, 19-25. 
Incyan, E. (1988, Novembre). "Plus proche des étudiants". Le Monde de L' Educacion, 60-66. Jarousse, J. (1984). “Les contraditions de l'Université de masse dix ans aprés (1973-1983)”. Révue française de sociologie, XXV, 191-210.

Knapper, C. \& Cropley, A. (1991). Lifelong Learning and higher Education. London: Kogan Page.

Le Bart, C. \& Merle, P. (1997). La citoyenneté étudiante - Intégration, participation, mobilization. Paris: PUF.

Menezes, I., Costa, M., \& Paiva Campos, B. (1989). "Valores de Estudantes Universitários". Caderno de Consulta Psicológica, 5, 53-68.

Molinari, J. (1992). Les étudiants. Paris: Les Éditions Ouvrières.

Moreira, J. (1993). Desenvolvimento Profissional dos Professores: A Educação das Preocupações e Motivações Profissionais. [Trabalho apresentado no âmbito das provas de Aptidão Pedagógica e Capacidade Científica]. Faculdade de Psicologia e de Ciências da Educação da Universidade de Lisboa.

Nico, B. (1995). A Relação Pedagógica na Universidade: ser-se caloiro. [Dissertação apresentada à Universidade de Lisboa tendo em vista a obtenção do grau de Mestre em Ciências da Educação]. Lisboa: Faculdade de Psicologia e de Ciências da Educação da Universidade de Lisboa (policopiada).

Nico, B. (1996). "A identidade vocacional em alunos universitários - um estudo de caso". In Albano Estrela \& Júlia Ferreira (Orgs.). Formação, Saberes Profissionais e Situação de Trabalho - Actas do VI Colóquio Nacional da Secção Portuguesa da AIPELF/AFIRSE. Lisboa: Universidade de Lisboa, 105-116.

Nico, B. (2001). Tornar-se estudante universitário(a): contributo do Conforto Académico na definição de uma estratégia curricular de sucesso. [Tese apresentada à Universidade de Évora tendo em vista a obtenção do grau de Doutor em Ciências da Educação]. Évora: Universidade de Évora (policopiada).

Snyders, G. (1993). Heureux à I' université. Paris: Ed. Natham.

Stern, M. (1992). "La nouvelle majorité: une population d' étudiants plus agés et son incidence sur l'université d'aujourd'hui". Gestion de l'enseignement supérier, (4), 1 